\title{
La colección de documentos Organización Nacional, 1861-1888 en el Servicio Histórico del Ejército Argentino
}

The collection of documents National Organization, 1861-1888 in the

Historical Service of the Argentine Army

\section{Lucas Codesido}

\section{OpenEdition}

Journals

\section{Electronic version}

URL: https://journals.openedition.org/corpusarchivos/4875

DOI: $10.4000 /$ corpusarchivos. 4875

ISSN: 1853-8037

\section{Publisher}

Diego Escolar

\section{Electronic reference}

Lucas Codesido, «La colección de documentos Organización Nacional, 1867-1888 en el Servicio Histórico del Ejército Argentino», Corpus [En línea], Vol. 11, №. 1 | 2021, Publicado el 01 julio 2021, consultado el 03 julio 2021. URL: http://journals.openedition.org/corpusarchivos/4875

This text was automatically generated on 3 July 2021.

Licencia Creative Commons: Atribución-NoComercial 2.5 Argentina (CC BY-NC 2.5 AR) 


\title{
La colección de documentos
} Organización Nacional, 1861-1888 en el Servicio Histórico del Ejército Argentino

\author{
The collection of documents National Organization, 1861-1888 in the \\ Historical Service of the Argentine Army
}

Lucas Codesido

\section{EDITOR'S NOTE}

Fecha de recepción del original: 19/04/2021

Fecha de aceptación para publicación: 10/6/2021

\section{Introducción}

1 En este breve recorrido descriptivo vamos a dar cuenta de una de las fuentes documentales ubicada en el Servicio Histórico del Ejército, nos referimos a la colección “organización Nacional, 1861-1888", compuesta por 87 cajas de madera con documentación original del Ministerio de Guerra que corresponde al período señalado. Vamos a trazar una relación de la procedencia de estos documentos, con vistas a comprender quienes los hacían, los modos de construcción de esa información y, en algún caso, señalar la forma de circulación institucional de esas comunicaciones. Seguidamente describimos algunas características significativas de esos documentos y su utilización en nuestro trabajo.

Debemos precisar que la perspectiva que adoptamos está atravesada por el objetivo general de nuestro trabajo de investigación, que se propone como aporte a la 
construcción del Estado argentino, examinando el rol del ejército en ese proceso. En esta tarea vinculamos el papel que desempeñó la violencia armada y el accionar de los agentes del Estado en formación en torno de la edificación de un ejército también nacional, en un contexto de militarización de la vida política argentina. Al consultar este archivo lo hicimos desde una indagación que partía de la asociación entre la violencia como mecanismo de resolución de las diputas y los procesos de construcción estatal, donde la guerra y la política aparecen estrechamente vinculadas. ${ }^{1} \mathrm{En}$ un nivel general, nos ha facilitado material para comprender muchas de las razones esgrimidas por los actores políticos del período, sus opiniones y fundamentos acerca de la definición de las facultades militares en el marco de las disputas por su potestad e incumbencias, entre la nación y las provincias, durante la construcción del sistema republicano. ${ }^{2}$

3 En el Servicio Histórico del Ejército existe de una gran cantidad de documentación oficial de las actividades del Ministerio de Guerra y Marina. Entre ellas, hemos examinado una parte importante (hasta 1881) de las 87 cajas de material clasificado como Organización Nacional,1861-1888. Si bien este recorte cronológico incluye fuentes que ocupan casi toda la década de 1860, debemos señalar que sobre el período de 1870 en adelante la colección posee un caudal de documentos mucho mayor al de la etapa mitrista o anterior a la Guerra de la Triple Alianza (1865-1870). Para esta época posterior cada una de las cajas contiene alrededor de dos meses de documentación producida, intervenida, presentada y archivada por el Ministerio de Guerra y Marina.

4 La colección está compuesta por una numerosa cantidad de testimonios y fuentes de diversa índole: partes militares, órdenes generales, actos de justicia militar, leyes, decretos, disposiciones, convocatorias a enrolamiento o movilización de la Guardia Nacional y otra enorme cantidad de disposiciones e intercambios acerca de múltiples temas, que incluyen entre otros, cartas de familiares, madres, padres, hermanos, de empleadores de individuos que han sido destinados al Ejército de Línea, dirigidas a distintos jefes militares, jueces de paz, al ministerio de Guerra o Comandancia de Armas. El trabajo con esa documentación nos ha permitido informarnos sobre el funcionamiento de la estructura militar tanto en épocas de relativa paz como en el contexto de un enfrentamiento armado. También nos ha proporcionado material para analizar la relación entre la guerra y la sociedad, mostrando la presencia del fenómeno de la movilización militar y la violencia en la vida cotidiana. Con ello hemos podido reconocer y distinguir diversos mecanismos y estrategias de resistencia de los sectores populares frente a la presión reclutadora.

5 La clasificación de esta documentación está organizada en carpetas que contienen las denominaciones siguientes: Política interna y causas, Administración, Organización y operaciones y Abastecimiento. La sección Política interna y causas es la que se destaca pues posee una mayor cantidad, diversidad y riqueza de documentación que las restantes. En ella encontramos todo tipo de expedientes sobre el personal militar, trámites, causas, y su seguimiento hasta el trascurso de su resolución, vinculados mayormente con la situación de la tropa y los oficiales. La ubicación cronológica de la documentación nos ha permitido revisar la política militar en las semanas y días previos de los episodios militares destacados en el período, junto con las diversas disposiciones dictadas por la urgencia mientras los mismos se producen y la política militar posterior, a partir de los resultados y sus consecuencias. Si tomamos por ejemplo el caso de la revuelta mitrista iniciada en septiembre de 1874 , en relación con la tropa, durante las semanas 
posteriores a los hechos de armas vemos multiplicarse en esta documentación las solicitudes de baja por parte de familiares o personas vinculadas con los soldados destinados luego de la rebelión. ${ }^{3}$ También se pueden observar las idas y vueltas de muchos de esos expedientes entre el Ministerio de Guerra, la Inspección y Comandancia General de Armas, las unidades donde sirven los destinados, o los miembros de la sociedad civil que reclaman por la suerte de esos soldados, y además las respuestas que desde el Ministerio de Guerra o la Inspección y Comandancia General de Armas se dan a esos pedidos, si es que son contestados. ${ }^{4}$ Durante esos años llegan al Ministerio de Guerra y a la Comandancia solicitudes de baja de soldados que han cumplido el servicio desde hace cuatro, seis y hasta diez años. ${ }^{5}$ Respecto de los oficiales, durante la rebelión mitrista, luego de ser dados de baja como partícipes y posteriormente indultados, aparecen durante las semanas posteriores a la publicación de los indultos a los jefes principales, solicitudes de otros oficiales de menor jerarquía dirigidas al Ministerio de Guerra, donde piden ser reincorporados al ejército. ${ }^{6}$ Las singularidades que contienen aquellas causas militares nos han brindado evidencias para la reflexión sobre las diferencias notables existentes en torno de las penalidades impuestas a quienes ejercen el mando, respecto de las condenas otorgadas a los miembros de la tropa. El tratamiento dado a unos y otros en las disposiciones legales nos ha permitido vincular diversas alusiones o representaciones que describen a los cuerpos de línea como órganos de punición, con la materialidad de los procesos y sumarios concretos asentados en los archivos. Encontramos que el castigo para los soldados implicados en las fuerzas rebeldes es el recargo en el servicio, compartiendo el destino en la tropa, junto con los civiles detenidos en la misma situación, mientras que las condenas dadas a los oficiales podían implicar la exoneración, baja del servicio o la pérdida del grado militar.

6 En la misma sección Política interna y causas existe una nutrida documentación que refleja la trayectoria del Colegio Militar de la Nación en sus primeros años de existencia. Se pueden encontrar diversos registros relativos a los quehaceres diarios de la institución, entre los que destacan varios expedientes disciplinarios que muestran incidentes protagonizados por alumnos del colegio y reflejados en sumarios internos que luego han sido elevados al Ministerio de Guerra. Estos incluyen causas como la deserción, ataques vandálicos a los transeúntes, denuncias por parte de padres de alumnos contra la violencia ejercida por algún profesor, un sumario a otros estudiantes que "estropearon gravemente a un compañero", y hasta un "proceso levantado para esclarecer los grados de culpabilidad de varios aspirantes acusados de entregarse, casi sin reserva, al asqueroso vicio de la sodomía" (Caja 66, 1877). Las penas que registran los casos resueltos comprenden diversos grados de severidad que van desde la suspensión de recreos, hasta la sanción de arresto por 24 horas y llegando hasta 6 meses, o bien, la baja del Ejército y expulsión del colegio. ${ }^{8}$ Las sanciones de expulsión de la institución acompañada de la prohibición de formar parte del Ejército, dadas a las faltas consideradas más graves, fueron disposiciones cuya decisión final recayó en el Presidente de la Nación. ${ }^{9}$

7 En la sección Administración podemos encontrar: cartas de familiares con reclamos de haberes de hijos o hermanos muertos, notas con enumeración de gastos de tropas acampadas (caja 44, 1870), filiaciones de individuos destinados, intercambio de notas entre el ministerio y los gobiernos provinciales acerca del enrolamiento de la Guardia Nacional (caja 54, 1870); reclamo de proveedores, disposiciones de movilización de la Guardia Nacional en distintos puntos del país (caja 55, 1875); pedidos de fondos de 
enganche, reclamos de particulares por los daños ocasionados por la revolución de 1874 (caja 58, 1875); deudas reclamadas por el ferrocarril, por el transporte de tropas durante la revolución de 1880 (caja 76: 1880).

En la sección Organización y operaciones: partes militares de las batallas contra López Jordán (caja 44, 1870); individuos huyendo de la montonera mitrista, pedidos de familiares por destinados al servicio de armas. Armas en depósito (caja 51, 1874); problemas para la confección del proyecto de código de justicia militar a causa de un incendio (Francisco Pico), también aquí aparecen pedidos de baja de soldados cumplidos del servicio (caja 53, 1875); notas sobre enganche y reclutamiento (caja 55, 1875); designaciones, ofrecimientos y respuestas, programa de materias de la escuela naval (caja 56, 1875); presupuestos para publicar leyes decretos y actos de gobierno en los diarios "La Tribuna" "La República" y "El comercio del Plata" (caja 58, 1875); lista de mujeres que componen la familia de los integrantes del regimiento 3 de caballería, pedidos por ciudadanos que no llegan a enrolarse (caja 69, 1878); alumnos del Colegio Militar propuestos para integrarse a las unidades, solicitud de manuales de cabos y sargentos para distintas unidades, listas de "indios que van a depósito" en Martin García (cajas 70-74, 1878); admisión al Colegio Militar, pedidos de baja de extranjeros por parte del consulado italiano, resultados del enganche de tropas (caja 71, 1879); recuento de existencias de rifles y carabinas Remington (caja 73, 1879). Respecto de la llamada Campaña del Desierto y las política de avance de la frontera con las sociedades indígenas, en las mismas carpetas denominadas Organización y operaciones hallamos distintos documentos con notas intercambiadas entre los jefes de las unidades en campaña, el inspector y comandante general de armas -Luis María Campos- y el jefe militar de Martín García -Donato Álvarez- encargado de los "indios en depósito", como se denominaba a los indígenas detenidos que eran enviados a la isla. Allí puede leerse por ejemplo que los indios devueltos a Martin García por "inútiles" para el servicio militar, serán "indios en depósito" o "indios presos". Los que son destinados llegan a las unidades como "indios presos" o "destinados a seis años de servicio como pampas", es decir condenados por su condición de indios. ${ }^{10}$

En la sección Abastecimiento: aparecen reclamos de proveedores luego de la revolución -1874- (caja 56, 1875); propuestas de racionamiento para instalar una colonia militar en Mendoza (caja 67, 1877); pedido de armas de precisión del gobierno de Catamarca (caja $72,1879)$; detalle de raciones para soldados y familias en las campañas al desierto, descripción de la fabricación de cañones tipo Krupp en el arsenal militar (caja 73, 1879). Hay que señalar que en esta misma caja y sección Abastecimiento figura el reparto de “indias viejas" y "criaturas ciegas por la viruela" entre el personal militar (caja 73, 1879). El gobierno de buenos aires vende remanente de armas a la nación, cañones incautados a Buenos Aires luego de la revolución -1880- (caja 76, 1880). Por último, en la sección Vestuario hay muy poco material, se hallan solicitudes de diversas prendas (caja 56, 1875); confección de monturas para caballo, contrato para Fabricación de paño (caja $67,1877)$.

\section{Otros documentos consultados en el Servicio Histórico}

En el Servicio Histórico se conservan las memorias presentadas al Congreso por el Ministerio de Guerra y Marina (consultamos el período1862-1881). ${ }^{11}$ Esas memorias 
reproducen una parte de la información que encontramos en la colección Organización Nacional, proporcionando datos sobre los movimientos de entradas y salida de personal, partes militares de los diversos enfrentamientos, reclutamiento para el Ejército de Línea, abastecimiento de tropas, el estado de los arsenales y almacenes, comisaría de guerra, actividades en la frontera, enrolamiento y movilización de la Guardia Nacional, Colegio Militar y diversos proyectos tendientes a la profesionalización de las Fuerzas Armadas. En el Servicio Histórico además están depositados los registros de altas y bajas que existen de algunos cuerpos del ejército, despachos de toma de razón y los tomos de órdenes generales. Material provechoso para reconstruir los movimientos de entradas y salidas, altas y bajas, del personal de tropa de aquellas unidades en el transcurso de más de una década en algún caso. En muchos de ellos se registra el origen de los reclutados, destinados por delitos, voluntarios, enganchados, reenganchados, cuestión que permite contrastar con algunos números concretos la correspondencia entre las representaciones sociales acerca del servicio militar utilizado como castigo y las evidencias encontradas (Codesido, 2019). En los libros de Órdenes de Cuerpo se registran las actividades diarias en las unidades, donde se anotan las tareas a realizar, las novedades ocurridas en los días previos, los problemas disciplinarios, los actos de justicia militar y el modo en que han sido resueltos, se registran las bajas por deserciones, enfermedades o en combate y diversas cuestiones relacionadas con el mantenimiento de las instalaciones y que permiten vislumbrar las condiciones de vida de la tropa. Sobre La Guerra de la Triple Alianza se encuentran cuatro colecciones de documentos: 1. Cajas Guerra del Paraguay: Son 63 cajas ordenadas cronológicamente (1864 a 1877) de las cuales solo 37 han sido fichadas. ${ }^{12} 2$. Semanario de Asunción: Copias de ejemplares del periódico paraguayo "El Semanario", de 1854 a 1867 (Son tres cajas parcialmente fichadas). 3. Temas específicos: Cuatro cajas con copias de documentos relacionados con la guerra, pero reunidos en recopilaciones de acuerdo a temas específicos (diplomacia, operaciones militares, etc.) 4. Bibliorato Armario blanco: Biblioratos con contenido diverso (listas de revista, registros de guerreros, libros copiadores, libros de órdenes, etc.) originales y copias.

\section{Conclusión}

11 En el presente artículo nos propusimos dar cuenta, a partir de un balance situado mayormente en la década de 1870, de la importancia de la colección Organización Nacional, 1861-1888, ubicada en el Servicio Histórico del Ejército. Referimos el tipo de documentación depositada y algunas particularidades descubiertas a partir de su empleo en nuestro trabajo. Aunque no intentamos ejecutar una revisión completa y exhaustiva, quisimos señalar algunas notas significativas respecto de las características y naturaleza de los registros hallados, mostrando el tipo de información y el contexto de producción en el que emergen esas fuentes. Para finalizar, consideramos que la colección Organización Nacional es un repertorio documental relevante en donde se pueden encontrar fuentes provechosas a los fines de las investigaciones sobre las fuerzas armadas, la violencia política, los procesos de construcción estatal y también útil a los estudios culturales acerca de la guerra y sus derivaciones sociales, normativas e institucionales, entre otras diversas posibilidades de abordaje. 


\section{BIBLIOGRAPHY}

Clausewitz, C. V. [1832] (1970) De la guerra, Buenos Aires: Círculo Militar, 4 tomos.

Codesido, L. (2019). Los presos soldados, sus jefes y el Estado: La construcción de la obediencia en el Ejército de Línea (Argentina, 1862-1882). Historia Caribe, XI (35), 2019, 114-151. Disponible en:

http://investigaciones.uniatlantico.edu.co/revistas/index.php/Historia_Caribe/article/view/ $2288 / 2934$

Codesido, L. (2021). La educación militar en tiempos de guerra. Los orígenes del Colegio Militar de la Nación (Argentina, 1869-1880). Revista de Historia de América, Instituto Panamericano de Geografía e Historia, OEA, 160, 2021, 111-139. Disponible en: https://revistasipgh.org/index.php/ rehiam/article/view/840/1506

Codesido, L. (2021). 1874. El Ejército Nacional frente al dilema mitrista. Entre la disputa facciosa y la subordinación al Estado. Prohistoria, 35, 2021, 29-54. Disponible en: https://ojs.rosarioconicet.gov.ar/index.php/prohistoria/article/view/1401/1742

Codesido, L. (2021). El proceso judicial contra el mitrismo rebelde. Entre la tradición militar española y la Conciliación de los partidos (1874-1877). Pasado Abierto, CEHis, Universidad Nacional de Mar del Plata, 13, 2021, 203-218. Disponible en: http://fh.mdp.edu.ar/revistas/index.php/ pasadoabierto/article/view/4485/5373

Escolar, D. (2007). Los dones étnicos de la nación. Buenos Aires: Prometeo.

Foucault, M. (1996). Genealogía del racismo. Buenos Aires: Caronte Ensayos.

Prado, M. (1942). La guerra al malón (1877-1879), Buenos Aires: Biblioteca clásica americana.

Sabato, H. (2008). Buenos Aires en armas. La revolución de 1880. Buenos Aires: Siglo XXI.

Tilly, C. (1993). Coerción, capital y los Estados europeos 990-1990. Buenos Aires: Alianza Editorial, 1993.

\section{Datos del Servicio Histórico del Ejército:}

TIPO DE ARCHIVO: Archivo Histórico Militar Nacional

NOMBRE ALTERNATIVO: SHE

SERVICIOS: Sala de consulta. Biblioteca. Referencia. Orientación a distancia.

HORARIOS: lunes a viernes de 8 a $13 \mathrm{~h}$.

DIRECCIÓN: Defensa 628 / 630, Ciudad de Buenos Aires

Correo electrónico: archivohistoricoea@gmail.com

VOLUMEN DOCUMENTACIÓN: 650 metros lineales aproximadamente.

ANEXOS: No posee

\section{NOTES}

1. Una dimensión que aparece en nuestra investigación es la relación entre guerra y política. Según nos dice Michel Foucault "la política es la guerra continuada por otros medios" (Foucault, 1996: 216). Con esta frase invierte la tesis de Clausewitz formulada a principios del siglo XIX en su ensayo "De la guerra". El trabajo de Charles Tilly es otro de los referentes conceptuales de la 
investigación que llevamos a cabo, aunque su análisis es distinto al que realiza Foucault, Tilly entiende a la guerra como motor del estado, mostrando que los períodos de intensa actividad militar estuvieron directamente relacionados con innovaciones políticas importantes (Tilly, 1993).

2. Las diputas entre el Estado nacional y las provincias, entre el modelo militar representado por el Ejército de Línea frente al que vehiculizaba la Guardia Nacional, expresaba la opción por modelos de Estado alternativos (Sabato, 2008).

3. En las peticiones se repite una figura similar cuando los familiares de los individuos destinados a las fuerzas de línea aseguran que los rebeldes los habían llevado a la fuerza antes, y ahora como castigo hace lo mismo el gobierno. Otras voces protestan por ser destinados al no haberse presentado al llamado a los cuarteles de la Guardia Nacional o por ser detenidos cerca de una partida enemiga (Codesido, 2016).

4. En los expedientes que pudimos examinar, pocas veces se otorga la baja a un soldado y ello luego de un largo trámite que solía demorarse -o perderse- en las redes de la burocracia. Un familiar o el propio soldado con la autorización de su jefe, podían pedir la baja que se elevaba a la Inspección y Comandancia de Armas, que luego requería el informe del jefe de la unidad sobre los antecedes del soldado. El trámite solía ir y volver varias veces desde el Ministerio de Guerra hacia la unidad en la que servía el soldado cumplido.

5. A veces la baja solicitada llegaba primero a las listas de revista de la Comisaria de Guerra, pero no se hacía efectiva en la unidad donde sirve el soldado y se les dejaba de abonar el sueldo. Cuando estos reclaman su paga se enteran que ya no figuran en lista y deben gestionar otro pedido de baja o un nuevo contrato o reenganche. Esto último es más rápido y a ello serán inducidos ante la posibilidad de volver a aparecer en la lista del comisario pagador. De esa manera son reenganchados soldados que viven largos años en la tropa de línea. Manuel Prado resumía ese destino señalando que "en tiempo de guerra no hay más baja que para el otro mundo" (Prado, 1942: 21-22).

6. En la mayoría de los casos esos pedidos fueron aceptados y los oficiales puestos nuevamente en funciones conservando el mismo grado militar que tenían antes del levantamiento iniciado el 24 de septiembre de 1874 (Cajas 67 y 68, 1877).

7. Los diversos reclamos, expresados en forma de solicitudes de baja para los miembros de la tropa y en pedidos de alta o reincorporación por parte de los oficiales castigados, muestran el servicio militar en la tropa como expresión de un castigo que puede prolongarse indefinidamente, mientras que la pertenencia al cuadro de oficiales aparece como un privilegio del que se puede ser despojado (Codesido, 2019: 130).

8. Esta última medida se tomó solo en algunos casos que tomaron estado público a raíz de una polémica que involucraba a dos facciones de estudiantes del colegio enfrentadas a través de los periódicos porteños. La disputa que provoco el sumario interno y las posteriores expulsiones se originó al formarse una comisión de alumnos del Colegio Militar encargados de la colecta de fondos para la repatriación de los restos del General San Martín. Una comisión fue designada de manera oficial por el presidente Avellaneda, apareciendo en una serie de solicitadas en diversos diarios. Otro grupo de alumnos publicó el 7 de abril de 1877 una nota en El Porteño, periódico de Héctor Varela, donde se acusaba de usurpadores y falsos patriotas que engañaron al Presidente para reivindicarse como comisión oficial y obtener dinero con fines espurios. Sobre estos últimos recayeron las sanciones.

9. Estos protocolos nos han permitido reflexionar acerca del control del ejército y su sometimiento a la autoridad presidencial, una característica que parece estar plasmada en la génesis de su normativa y que coincide con las ideas impulsadas por D. F. Sarmiento desde la presidencia de la nación (1868-1874). Diversas resoluciones del presidente Avellaneda (Caja 66, 1877). 
10. Cuando un jefe reclama a la Inspección de Armas que remita indicaciones sobre un grupo de indios para emitir sus filiaciones, el general Campos responde: "avísese que los indios son siempre destinados por seis años" (Caja 72, 1879). Parece ser toda la información que el jefe que los recibe necesita conocer. Estas fuentes nos han proporcionado material para reflexionar acerca de la diferencia en la consideración de los indígenas destinados respecto de los soldados vencidos en las guerras civiles del período. Esa discriminación aparece confirmada en las formas como son condenados al servicio militar. En episodios anteriores, durante las guerras jordanistas o en el levantamiento mitrista, debido a la naturaleza política de los enfrentamientos, las tropas de los vencidos se incorporaban en calidad de reos, destinados por rebeldes o sediciosos. En el caso de los indígenas, no eran reos políticos ni sediciosos porque se los había excluido de la contienda político-facciosa y aparecían en un horizonte cultural que los situaba del otro lado de la civilización. Aunque, según cambian las circunstancias, la idea del exterminio de la barbarie indígena en otros documentos puede convivir con su opuesta, la de integrar a los indígenas valorando sus aptitudes para el trabajo o la carrera militar. Estas se proponían para integrar o segregar a los actores subalternos según una coyuntura específica constituyendo "una etnicidad sin grupos étnicos" (Escolar, 2007) que intenta configurar diversas identidades en sujetos que con frecuencia pertenecen a las mismas poblaciones.

11. No hubo presentación de memorias para los años 1867, 1874 y 1880 . En 1867 debido a las rebeliones en el interior luego de la derrota de Curupaytí y en 1874 y 1880 el Ministerio de Guerra no hizo las memorias de sus actividades pasadas y futuras a causa de la agitación producida por los procesos electorales que desembocaron en las dos guerras que marcaron esas fechas: contra los mitristas en 1874 y frente a las fuerzas de Tejedor en 1880.

12. No estaban disponibles para consulta en agosto de 2019 , cuando las requerimos.

\section{ABSTRACTS}

In this paper we propose to give an account of the importance of the collection of archives "National Organization, 1861-1888" located in the Historical Service of the National Army in Argentina. For this reason, we make a description of the origin of these documents and we highlight some specific characteristics discovered from the exhaustive review and their use in our work.

En este artículo nos proponemos dar cuenta de la importancia de la colección de archivos “Organización Nacional, 1861-1888" ubicada en el Servicio Histórico del Ejército Nacional en la Argentina. Con tal motivo, hacemos una descripción de la procedencia de estos documentos y destacamos algunas características específicas descubiertas a partir de la revisión exhaustiva y su utilización en nuestro trabajo.

\section{INDEX}

Palabras claves: organización nacional, archivos, documentos, ejército argentino, siglo XIX. Keywords: national organization, archives, documents, argentine army, 19th century. 
AUTHOR

LUCAS CODESIDO

Departamento de Derecho y Ciencia Política

Universidad Nacional de la Matanza, Argentina

Correo electrónico: lcodesid@campus.ungs.edu.ar 